\title{
The Growing Role of Nuts and Seeds in Human Health
}

\author{
Mahendra Pal ${ }^{\star}$ and Judit Molnar ${ }^{2}$ \\ ${ }^{I}$ Narayan Consultancy on Veterinary Public Health and Microbiology- Anand, Gujarat, India \\ 2SzéchenyiIstván University, Faculty of Agricultural and Food Sciences, Department of Water and Environmental Sciences - \\ Mosonmagyaróvár, Europe
}

Article Info

*Corresponding author:
Mahendra Pal
Professor
Director of Narayan Consultancy on
Veterinary Public Health and Microbiology
Gujarat, India
E-mail: palmahendra2@gmail.com

Received: December 01, 2021

Accepted: December 13, 2021

Published: December 17, 2021

Citation: Pal M, Molnar J. The Growing Role of Nuts and Seeds in Human Health. Madridge J Food Technol. 2021; 6(1): 187-188. doi: $10.18689 / \mathrm{mjft}-1000128$

Copyright: ( $₫ 2021$ The Author(s). This work is licensed under a Creative Commons Attribution 4.0 International License, which permits unrestricted use, distribution, and reproduction in any medium, provided the original work is properly cited.

Published by Madridge Publishers

\begin{abstract}
Nutrionally good diet is imperative to mainatin good health. Nuts and seeds have been recongnized to reduce the development of many diseases, such as tumors, high cholesterol, type II diabetes, dementia in old age, fetal malformations) due to their content of vitamins (vitamins E and B), minerals (potassium, calcium, iron, zinc, selenium, magnesium, phosphorus), omega-3 fatty acids, protein, and fiber. Therefore, they can be well integrated into healthy eating and many nutritional trends like the Mediterranean diet, and can also be used for cooking. Due to these reasons, our manuscript focuses on the properties of almond, walnuts, cashew nuts, pumpkin seeds, flax seeds, and sunflower seeds.
\end{abstract}

Keywords: Almonds; Walnuts; Cashew nuts; Flax seeds; Healthy eating; Nuts; Pumpkin seeds; Seed; Sunflower seeds; Walnuts.

\section{Introduction}

Nowadays, a healthy nutrition plays a significant role in healthy lifestyle, for which a number of recommendations have been made by earlier workers [1]. These recommendations also mention the consumption of seeds and nuts, which contribute to the maintenance of health with their useful content values [2]. These contents include fiber, antioxidants, proteins, omega-3 fatty acids, vitamins and minerals. Due to their useful active ingredients, they reduce the chances of developing many diseases like cardiovascular diseases, dementia in old age, gastrointestinal diseases or osteoporosis [3]. Furthermore, their consumption can be well integrated into special diets, such as the Mediterranean diet [4].

Among the nuts, almonds, hazelnuts, walnuts, pecans, pine nuts, cashew nuts are well known. Outstanding seeds include pumpkin seeds, flax seeds, sesame seeds, sunflower seeds, and chia seeds. Among these seeds and nuts, our manuscript summarizes the most important properties of almonds, walnuts, cashew nuts, pumpkin seeds, flax seeds, and sunflower seeds.

\section{Key characteristics and health effects of almonds, walnuts, cashew nuts, pumpkin seeds, flax seeds and sunflower seeds}

Almonds: Fiber, amino acids, zinc, magnesium, potassium, phosphorus, iron, copper, selenium, as well as vitamins (vitamins $E$ and $B$ ) and omega- 3 fatty acids play a significant role in the prevention of cardiovascular disease, among others. Furthermore, these beneficial components also contribute to the fetal development or the prevention of dementia in old age [5]. 
Walnuts: Walnuts are also high in useful fatty acids, vitamins $E$ and $B$, as well as manganese, zinc, magnesium, calcium, potassium and selenium. Thanks to its useful content, it has a good effect on the cardiovascular system and brain function, among other things [6]. Very recently, the nutritional and health benefits of consumption of walnut is described by [7].

Cashew nuts: Cashew nuts are an excellent source of vitamin $\mathrm{K}$, magnesium, phosphorus and iron. Its protein content is also outstanding and it also contains antioxidant active ingredients. Cashew nuts play a role in protecting the immune system. In addition, it reduces the risk of developing tumours among others [8].

Pumpkin seeds: Pumpkin seeds are also high in vitamins $B, E$, $\mathrm{K}$ and $\mathrm{C}$, as well as zinc, manganese, magnesium and iron. It also supports the immune system due to its phytosterol content, contributes to the prevention of high cholesterol, and prostate health [9].

Flax seeds: Flax seeds play a prominent role in the digestion. It contains significant amounts of $\alpha$-linolenic acid, fiber, manganese, magnesium, phosphorus, zinc and selenium. Flax seeds can contribute to a successful diet. In addition, it improves the cholesterol levels and also protects the cardiovascular system [10].

Sunflower seeds: Sunflower seeds are important in vitamin $E_{\text {, }}$ iron, selenium, zinc, copper and calcium, among others. It has a prominent role in the prevention of cardiovascular disease. It also helps in digestion due to its fiber content [11].

\section{Conclusion}

The seeds and nuts can be useful parts of a healthy daily diet or various nutritional trends. Outstanding among these is the Mediterranean diet. Almonds, walnuts, cashew nuts, pumpkin seeds, flax seeds and sunflower seeds possess several properties that contribute to the prevention of many diseases, such as cardiovascular, gastrointestinal or nervous system diseases. As a result, they play a significant role in preventing high cholesterol, cancer or dementia in old age, among other things. Consumption of nuts and seeds as an ingredient in dishes is also recommended. We hope that our paper will certainly contribute to a healthier lifestyle.

\section{Acknowledgements}

The authors are very grateful to Prof. Dr. R.K.Narayan for his suggestions during the preparation of manuscript and Anubha Priyabandhu for computer help.

\section{Conflict of interest}

The authors declare that they have no conflict of interest.

\section{References}

1. Skerrett PJ, Willett WC. Essentials of healthy eating: A guide. J Midwifery Womens Health. 2010; 55(6): 492-501. doi: 10.1016/j.jmwh.2010.06.019

2. Freitas JB, Fernandes DC, Czeder LP, et al. Edible seeds and nuts grown in Brazil as sources of protein for human nutrition. Food and Nutrition Sciences. 2012; 3: 857-862. doi: 10.4236/fns.2012.36114

3. Machado de Souza RG, Schincaglia RM, Pimentel GD, Mota JF. Nuts and human health outcomes: A systematic review. Nutrients. 2017; 9(12): 1-23. doi: $10.3390 /$ nu9121311

4. Sabaté J, Ang Y. Nuts and health outcomes: new epidemiologic evidence. Am J Clin Nutr. 2009; 89(5): 1643S-1648S. doi: 10.3945/ ajcn.2009.26736Q

5. Barreca D, Nabavi SM, Sureda A, et al. Almonds (Prunus Dulcis Mill D. A. Webb): A source of nutrients and health-promoting compounds. Nutrients. 2020; 12(3): 1-22. doi: 10.3390/nu12030672

6. Berryman $\mathrm{CE}$, Grieger JA, West SG, et al. Acute consumption of walnuts and walnut components differentially affect postprandial lipemia, endothelial function, oxidative stress, and cholesterol efflux in humans with mild hypercholesterolemia. J Nutr. 2013; 143(6): 788794. doi: 10.3945/jn.112.170993

7. Pal M. Walnut: A highly nutritious food with several health benefits. Food Nutrition Open Access. 2020; 3(1): 1-2. doi: 10.31021/fnoa.20203118

8. Baer DJ, Novotny JA. Metabolizable energy from cashew nuts is less than that predicted by Atwater factors. Nutrients. 2018; 11(1): 1-10. doi: $10.3390 /$ nu11010033

9. Dotto JM, Chacha JS. The potential of pumpkin seeds as a functional food ingredient: A review. Scientific African. 2020; 10: 1-14. doi: 10.1016/j.sciaf.2020.e00575

10. Parikh M, Maddaford TG, Austria JA, Aliani M, Netticadan T, Pierce GN Dietary Flaxseed as a strategy for improving human health. Nutrients. 2019; 11(5): 1-15. doi: 10.3390/nu11051171

11. Guo S, Ge Y, Jom KN. A review of phytochemistry, metabolite changes, and medicinal uses of the common sunflower seed and sprouts (Helianthus Annuus L.). Chem Cent J. 2017; 11(1): 95. doi: 10.1186/ s13065-017-0328-7 